Article

\title{
Lipid Peroxidative Damage on Cisplatin Exposure and Alterations in Antioxidant Defense System in Rat Kidneys: A Possible Protective Effect of Selenium
}

Branka I. Ognjanović ${ }^{1, *}$, Nataša Z. Djordjević ${ }^{1}$, Miloš M. Matić ${ }^{1}$, Jasmina M. Obradović ${ }^{1}$, Jelena M. Mladenovićc ${ }^{1}$, Andraš Š. Štajn ${ }^{1}$ and Zorica S. Saičić ${ }^{2}$

1 Institute of Biology and Ecology, Faculty of Science, University of Kragujevac, Radoja

Domanovića 12, 34000 Kragujevac, Serbia; E-Mails: natasadj@kg.ac.rs (N.Z.D.);

milosmatic@kg.ac.rs (M.M.M.); jasmina.m.obradovic@gmail.com (J.M.O.);

jelena.m.mlad@gmail.com (J.M.M.); astajn@kg.ac.rs (A.Š. ̌̌.)

2 Department of Physiology, Institute for Biological Research "Siniša Stanković", University of Belgrade, Bulevar despota Stefana 142, 11000 Belgrade, Serbia;

E-Mail: zorica.saicic@ibiss.bg.ac.rs

* Author to whom correspondence should be addressed; E-Mail: branka@kg.ac.rs;

Tel: +381-34-336-223; Fax: +381-34-335-040.

Received: 23 November 2011; in revised form: 23 January 2012 / Accepted: 31 January 2012 / Published: 8 February 2012

Abstract: Cisplatin (Cis-diamminedichloroplatinum II, CP) is an important chemotherapeutic agent, useful in the treatment of several cancers, but with several side effects such as nephrotoxicity. The present study investigated the possible protective effect of selenium (Se) against CP-induced oxidative stress in the rat kidneys. Male Wistar albino rats were injected with a single dose of cisplatin ( $7 \mathrm{mg} \mathrm{CP} / \mathrm{kg}$ b.m., i.p.) and selenium (6 mg Se/kg b.m, as $\mathrm{Na}_{2} \mathrm{SeO}_{3}$, i.p.), alone or in combination. The obtained results showed that $\mathrm{CP}$ increased lipid peroxidation (LPO) and decreased reduced glutathione (GSH) concentrations, suggesting the CP-induced oxidative stress, while Se treatment reversed this change to control values. Acute intoxication of rats with $\mathrm{CP}$ was followed by statistically significant decreased activity of antioxidant defense enzymes: superoxide dismutase (SOD), catalase (CAT), glutathione peroxidase (GSH-Px), glutathione reductase (GR) and glutathione-S-transferase (GST). Treatment with Se reversed CP-induced alterations of antioxidant defense enzyme activities and significantly prevented the CP-induced kidney damage. 
Keywords: cisplatin; selenium; nephrotoxicity; lipid peroxidation; antioxidant defense system

\section{Introduction}

Cisplatin (cis-diammine-dichloroplatinum II, CP) has been considered one of the most effective chemotherapeutic agents, utilized for treatment of a variety of human solid tumors. Activity has been demonstrated against a variety of tumors, particularly of head and neck, ovarian, testicular, esophageal, bladder and small cell lung cancers [1]. The clinical use of CP is often limited due to its undesirable side effects, nephrotoxicity and neurotoxicity being the most severe and dose-limiting ones [2]. $\mathrm{CP}$-induced kidney damage is associated with increased kidney vascular resistance and histological damage to proximal tubular cells $[1,3,4]$. The cytotoxicity of $\mathrm{CP}$ is considered to be due to a combination of factors, including peroxidation of the cell membrane, mitochondrial dysfunction, inhibition of protein synthesis, and DNA injury $[3,5,6]$. The most common adverse effect limiting the use of CP is nephrotoxicity that develops primarily in the S3 segment of the proximal tubule [7]. Although reactive oxygen species (ROS) have been considered to play a central role in this injury, the exact roles of free radicals and the mechanisms underlying the beneficial effects of free radical scavengers have not been fully evaluated $[1-3,8,9]$.

The pathogenesis of kidney damage caused by CP is generally considered oxidative damage [1,2]. Administration of CP causes an increase in lipid peroxide levels and a decrease in the activity of antioxidant defense enzymes that prevent or protect from lipid peroxidation in the tissues. Cisplatin accumulates in the tubular epithelial cells of proximal kidney tubule, causing nephrotoxicity, characterized by morphological destruction of intracellular organelles, cellular necrosis, loss of microvilli, alterations in the number and size of the lysosomes and mitochondrial vacuolization, followed by functional alterations including inhibition of protein synthesis, GSH depletion, lipid peroxidation and mitochondrial damage $[1,2,4,8-10]$.

Recent studies have focused on the role of antoxidants in CP toxicity. The administration of antioxidants and other agents have been shown to ameliorate $\mathrm{CP}$-induced toxicity in various species of animals [7,11-18].

Selenium (Se) is an essential trace element which plays an important role in a number of biological processes in humans and many other forms of life. Many experimental studies of animals have demonstrated that the deficiency of Se induces some pathological conditions (coronary heart disease, liver necrosis) and is an important risk factor in the etiologies of these diseases [19-23]. Biological and medical advances in the area of Se provide interest in Se for both its antioxidant properties through seleno-enzyme incorporation and its direct pro-oxidant toxic effect through seleno-compounds [21,22]. $\mathrm{Se}$ is an essential component of several enzymes such as glutathione peroxidase (GSH-Px), thioredoxin reductase (TR) and selenoprotein $\mathrm{P}(\mathrm{SeP})$, which contains Se as selenocysteine. It is also well known that $\mathrm{Se}$ is essential for cell culture when a serum-free medium is used [21-25].

Recent studies showed protective effects of $\mathrm{Se}$ against cadmium (Cd)-induced oxidative stress $[26,27]$. It has also been demonstrated that the chronic exposure to low levels of $\mathrm{Cd}$ and other toxic elements abolishes the cancer-protective effect of Se. An important property of Se is its 
interaction with other elements that may be present in food, water, at the workplace and in the environment. Se functions as an antagonist to the toxicity of metals such as $\mathrm{Hg}, \mathrm{Cd}, \mathrm{As}, \mathrm{Ag}, \mathrm{Pb}$ and $\mathrm{Cu}[28,29]$. The arsenic-, platinum- and gold-containing drugs significantly influence the fate of exogenous Se, whereby they may adversely affect the availability of this element, essential for synthesis of selenoenzymes [30].

The aim of the present study was to investigate a protective effect of Se pretreatment on lipid peroxidation (LPO) and reduced glutathione (GSH) concentrations and activity of antioxidant defense enzymes: superoxide dismutase (SOD), catalase (CAT), glutathione peroxidase (GSH-Px), glutathione reductase (GR), as well as glutathione-S-transferase (GST) in the kidney of rats, acutely treated with CP.

\section{Experimental Methods}

\subsection{Chemicals}

Cisplatin (cis-dichlorodiammine-platinum II, CP) and sodium selenite $\left(\mathrm{Na}_{2} \mathrm{SeO}_{3}\right)$ were purchased from Merck Chemical Inc. (Darmstandt, Germany). Nicotinamide adenine dinucleotide phosphate (reduced form; NADPH); reduced (GSH) and oxidized (GSSG) glutathione; 1-chloro-2,4-dinitrobenzene $(\mathrm{CDNB})$; tert-butyl hydroperoxide $(t \mathrm{BOOH})$; glutathione reductase; DTNB (5,5'-dithio-bis-2nitrobenzoic acid) and bovine serum albumin were purchased from Sigma Chemical Co. (St. Louis, MO, U.S.A). All other chemicals and reagents were of the highest commercially available purity.

\subsection{Animals and Treatments}

Male Wistar albino rats (about 3 months old, weighing 210-250 g) were used. The animals were kept under standard laboratory conditions (12 h light, $12 \mathrm{~h}$ dark and $\left.21 \pm 2{ }^{\circ} \mathrm{C}\right)$. All rats were housed in individual cages and given standard diet and tap water ad libitum. The University Committee of the Ethics of Animal Experimentation approved all animal experiments. The animals were divided into four groups ( $n=6$ per group) and treated as follows:

Group 1: Control rats, treated intraperitoneally (i.p.) with isotonic saline.

Group 2: Cisplatin (CP) (received i.p. a single dose of $7 \mathrm{mg} \mathrm{CP} / \mathrm{kg}$ b.w.).

Group 3: Selenium (Se) (received a single i.p. injection of $\mathrm{Na}_{2} \mathrm{SeO}_{3}$ in the dose of $6 \mathrm{mg} \mathrm{Se} / \mathrm{kg} \mathrm{b.w.).}$

Group 4: $\mathrm{Se}+\mathrm{CP}$ (treated by Se $1 \mathrm{~h}$ before $\mathrm{CP}$ injection in the above mentioned amounts).

After the treatment ( 3 days after CP injection) all animals were sacrificed by decapitation. The kidney tissues were quickly excised, rinsed in ice-cold saline and used immediately or stored frozen at $-80{ }^{\circ} \mathrm{C}$ until further biochemical analysis.

\subsection{Tissue Preparation}

The kidney tissues were minced and homogenized with a Thomas Sci Co. glass homogenizer (Teflon pestle) at $0-4{ }^{\circ} \mathrm{C}(10 \% \mathrm{w} / \mathrm{v})$ using $0.25 \mathrm{M}$ sucrose, $1 \mathrm{mM}$ EDTA and $0.05 \mathrm{M}$ Tris-HCl solution and $\mathrm{pH}$ 7.4. The homogenates were centrifuged $\left(90 \mathrm{~min}\right.$ at $10,000 \times \mathrm{g}, 4{ }^{\circ} \mathrm{C}$ ) and the supernatant was used for antioxidant defense enzyme activity assays and for total protein determination. 


\subsection{Biochemical Analysis}

\subsubsection{Lipid Peroxidation Assay}

Lipid peroxidation (LPO) was evaluated by measuring the MDA concentration. The tissues homogenates (using $1.15 \% \mathrm{KCl}$ ) were precipitated with trichloracetic acid. After centrifugation $(1500 \times g, 15 \mathrm{~min})$, the supernatant was mixed with TBA reagent $(0.6 \%)$ and the mixture was kept at $100{ }^{\circ} \mathrm{C}$ for $1 \mathrm{~h}$. The fluorescent reaction product was extracted with $n$-butanol and the fluorescence was measured in the organic phase, using a fluorescence spectrophotometer (excitation: $535 \mathrm{~nm}$ and emission: $555 \mathrm{~nm}$ ) [31]. These results were expressed in nmol MDA/g tissue using a molar extinction coefficient for MDA of $1.56 \times 10^{5} \mathrm{M}^{-1} \cdot \mathrm{cm}^{-1}$.

\subsubsection{Determination of Antioxidant Enzyme Activity}

Superoxide dismutase (SOD, EC 1.15.1.1) activity was assayed in the supernatant by the epinephrine method [32]. The method is based on the measurement of the rate of epinephrine auto-oxidation inhibition by SOD contained in the examined samples in $50 \mathrm{mM}$ sodium carbonate buffer $\mathrm{pH}$ 10.2, within the linear range of auto-oxidative curve. SOD activity was expressed as units/mg protein.

Catalase (CAT, EC 1.11.1.6) activity was measured by the method of Beutler [33]. The method is based on the rate of $\mathrm{H}_{2} \mathrm{O}_{2}$ degradation by the action of CAT contained in the examined samples and followed spectrophotometrically at $230 \mathrm{~nm}$ in $5 \mathrm{mM}$ EDTA, $1 \mathrm{M}$ Tris- $\mathrm{HCl}$ solution, $\mathrm{pH}$ 8.0. The enzyme activity was expressed in $\mu \mathrm{mol} \mathrm{H}_{2} \mathrm{O}_{2} \mathrm{~min} / \mathrm{mg}$ protein.

The activity of glutathione peroxidase (GSH-Px, EC 1.11.1.9) was determined using t-butyl hydroperoxide as a substrate by the method of Tamura et al. [34] and the activity was expressed as nmol NADPH oxidized/min/mg protein.

Glutathione reductase (GR, EC 1.6.4.2) activity was assayed by the method of Glatzle et al. [35] by measuring NADPH oxidation in the presence of oxidized glutathione and the activity was expressed as nmol NADPH oxidized/min/mg protein.

For determination of glutathione-S-transferase (GST, EC 2.5.1.18) activity, 1-chloro-2,4-dinitro benzene (CDNB) was used as a substrate [36] and the activity was expressed as nmol GSH used $\mathrm{min} / \mathrm{mg}$ protein.

\subsubsection{Reduced Glutathione (GSH) Assay}

The concentration of reduced glutathione (GSH) was measured by the method of Beutler [37]. Tissue samples for GSH assay were homogenized on ice with 20 volumes of precipitating solution

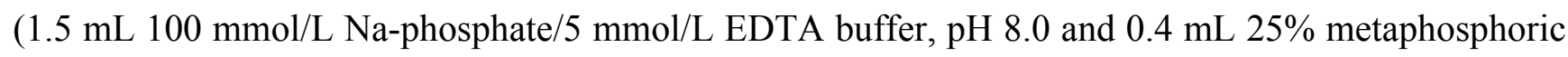
acid) and then centrifuged at $10,000 \mathrm{~g}$ for $30 \mathrm{~min}$ at $4{ }^{\circ} \mathrm{C}$. The reaction mixture contained $0.5 \mathrm{~mL}$ of supernatant, $0.75 \mathrm{~mL}$ of Na-phosphate puffer $(0.2 \mathrm{M}, \mathrm{pH} 7.4), 0.1 \mathrm{~mL}$ DTNB (5,5'-dithio-bis-2-nitrobenzoic acid) and $0.04 \mathrm{~mL} \mathrm{NaOH}$. The solution was kept at room temperature for $15 \mathrm{~min}$ and then read at $412 \mathrm{~nm}$ on a spectrophotometer. The concentration of GSH was expressed in $\mu \mathrm{mol} \mathrm{GSH} / g$ protein. 


\subsubsection{Protein Concentration Assay}

The concentration of total proteins was determined by the biuret method [38] using Folin's reagent and bovine serum albumin (BSA) as standard.

\subsection{Statistical Analysis}

All data are presented as means \pm SD. Statistical significance of the results was evaluated by using one-way ANOVA (analysis of variance) test and post-comparison was carried out with Student's $t$-test. A probability value less than $0.05(p<0.05)$ was considered statistically significant.

\section{Results}

The data presented in Table 1 show significant changes in the concentrations of LPO and GSH during the treatment of rats with $\mathrm{CP}$ and Se alone or in combination. The results showed that LPO concentration significantly increased in kidneys of rats treated with CP (by about $27 \%)(p<0.05)$ in comparison to control. Pretreatment with Se was very effective in the prevention of oxidative damage induced by CP, which resulted in significantly lower LPO concentration. Alone Se treatment had showed no significant effect. Exposure to CP caused significant decrease of GSH concentration by $25.6 \%(p<0.05)$ in kidney of rats, while Se treatment reversed this change to control values. No significant change in GSH was found in rats treated with $\mathrm{Se}+\mathrm{CP}$ and Se only in comparison with control group.

Table 1. Effect of Se treatment on LPO and GSH concentrations in kidneys of CP-treated rats.

\begin{tabular}{ccccc}
\hline \multirow{2}{*}{ Parameters } & \multicolumn{4}{c}{ Experimental groups } \\
\cline { 2 - 5 } & Control & CP & Se & Se + CP \\
\hline LPO (nmol MDA/g tissue) & $21.5 \pm 2.8$ & $27.3 \pm 3.4^{*}$ & $18.6 \pm 1.5^{\#}$ & $23.7 \pm 2.3^{\#}$ \\
GSH $(\mu \mathrm{mol} / \mathrm{g}$ protein) & $28.9 \pm 3.8$ & $21.5 \pm 3.1^{*}$ & $26.7 \pm 2.7^{\#}$ & $24.7 \pm 2.7^{\#}$ \\
\hline
\end{tabular}

Values are expressed as means $\pm \mathrm{SD} ; n=6$ for each treatment group; CP: Cisplatin; Se: selenium;

LPO: lipid peroxidation; GSH: reduced glutathione; * $p<0.05$ compared with control group, $\# p<0.05$ compared with CP group.

Acute intoxication of rats with $\mathrm{CP}$ was followed by statistically significant decreased activities of all examined antioxidant defense enzymes (SOD, CAT, GSH-Px, GR and GST), (Figures 1-5). As represented in Figures 1 and 2, the exposure to CP caused the decrease of SOD and CAT activities (by about $37 \%)(p<0.05)$ in kidney. In rats receiving Se only, and in rats pretreated with Se, the activities of SOD and CAT in kidney were similar to control values, but significantly increased (by about $21 \%$ and $26 \%)(p<0.05)$ in comparison to the animals which received CP only. 
Figure 1. Effect of Se treatment on superoxide dismutase (SOD) activity in kidney of $\mathrm{CP}$-treated rats. Values are expressed as means $\pm \mathrm{SD} ; n=6$ for each treatment group; CP: Cisplatin; Se: selenium; ${ }^{*} p<0.05$ compared with control group, $\# p<0.05$ compared with CP group.

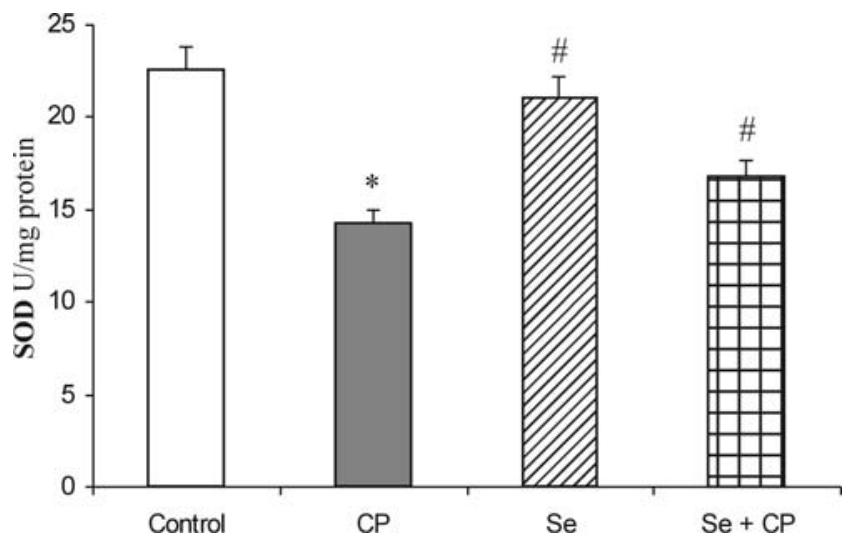

Figure 2. Effect of Se treatment on catalase (CAT) activity in kidney of CP-treated rats. Values are expressed as means $\pm \mathrm{SD} ; n=6$ for each treatment group; CP: Cisplatin; Se: selenium; $* p<0.05$ compared with control group, $\# p<0.05$ compared with CP group.

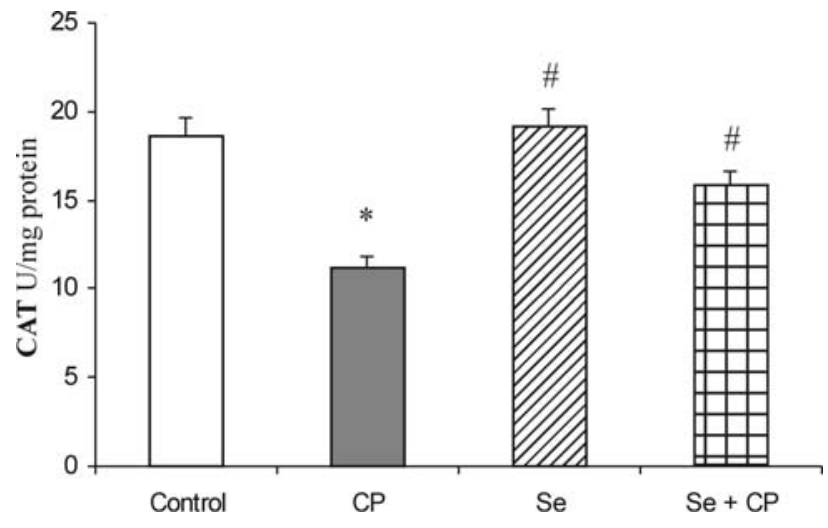

Figure 3. Effect of Se treatment on glutathione peroxidase (GSH-Px) activity in kidney of $\mathrm{CP}$-treated rats. Values are expressed as means $\pm \mathrm{SD} ; n=6$ for each treatment group; CP :Cisplatin; Se: selenium; ${ }^{*} p<0.05$ compared with control group, $\# p<0.05$ compared with CP group.

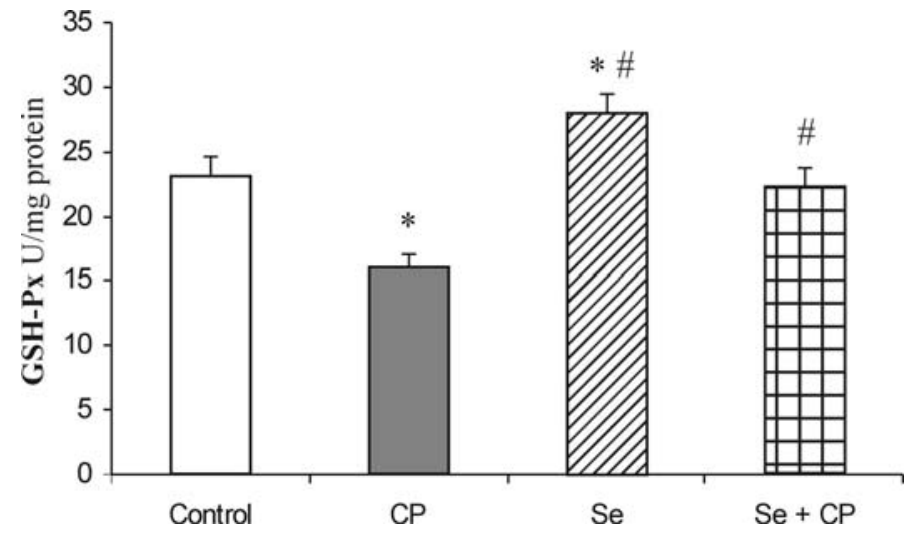


Figure 4. Effect of Se treatment on glutathione reductase (GR) activity in kidney of $\mathrm{CP}$-treated rats. Values are expressed as means $\pm \mathrm{SD} ; n=6$ for each treatment group; CP: Cisplatin; Se: selenium; ${ }^{*} p<0.05$ compared with control group, $\# p<0.05$ compared with CP group.

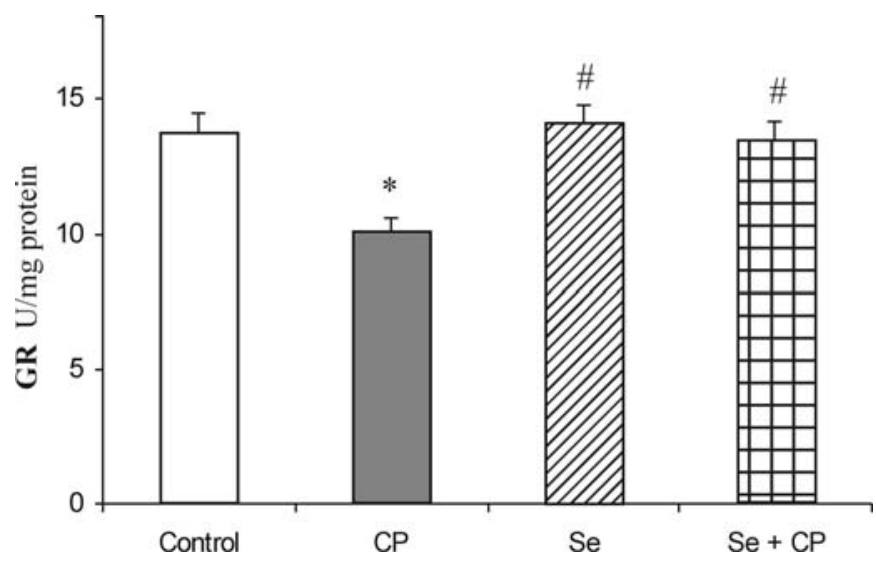

Figure 5. Effect of Se treatment on glutathione-S-transferase (GST) activity in kidney of CP-treated rats. Values are expressed as means $\pm \mathrm{SD} ; n=6$ for each treatment group; CP: Cisplatin; Se: selenium; ${ }^{*} p<0.05$ compared with control group, $\# p<0.05$ compared with CP group.

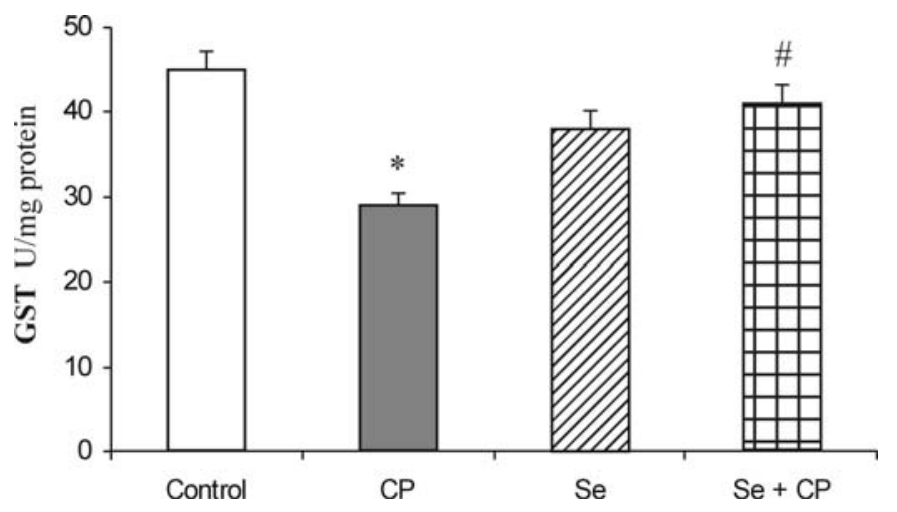

The exposure to CP caused a significant decrease of GSH-Px (by 32.1\%), GR (by 23.2\%) and GST (by 36.8\%) activities in comparison to control group $(p<0.05)$, (Figures $3-5)$. The protective role of Se in acute CP intoxication resulted in increased activities of GSH-Px (by about 25\%) (Figure 3), GR (by about 15\%) (Figure 4) and GST (by about 31\%) (Figure 5) when compared to the animals given $\mathrm{CP}$ alone. The presence of the antioxidants minimized the toxic effects of CP on the affected enzymes. Treatment with Se alone significantly increased GSH-Px activity in kidney in comparison to the control (by about 16\%) and CP-treated groups (by about 48\%). Administration of Se alone and/or in combination with $\mathrm{CP}$ did not cause significant changes in activity of GR and GST enzymes in comparison with control group.

\section{Discussion}

Cisplatin (CP), a heavy metal complex is one of the most active drugs used in the treatment of a variety of cancers. However, the clinical usefulness of this drug is limited due to the development of 
nephrotoxicity as a side effect that may be produced in various animal models $[2,16,18]$. The treatment of tumor cells with CP provokes several responses including membrane peroxidation, dysfunction of mitochondria, inhibition of protein synthesis and DNA damage [1,4-6,8-10]. The current study demonstrates that Se provides protection against CP-induced nephrotoxicity in rats.

The data obtained in our study confirm that acute intoxication with CP causes a significant increase of LPO concentration in the kidney of rats (Table 1). CP-induced free radical production and LPO in tubular cells have been suggested to be responsible for the oxidative renal damage $[1,3,8,14,39]$. CP affects renal tissues where generated free radicals can interact with membrane lipids to produce their peroxidation, affecting cellular structure and function [2,17,18]. Kim et al. [12] observed that CP could promote the increase in lipid peroxidation in vitro. Pretreatment with Se was very effective in the prevention of oxidative damage induced by $\mathrm{CP}$, which resulted in significantly lower LPO concentration in kidney. These results can be explained by the important role of Se in preventing lipid peroxidation and in protection of integrity and functioning of tissues and cells [13,20-23,26].

Therapeutic effects of CP are based on the interaction with DNA in the cell, preventing proliferation, and inducing apoptosis in tumor cells. It was also observed that $\mathrm{CP}$ treatment increased BUN (blood urea nitrogen) and creatinine levels. A marked increase in BUN and creatinine in serum and histopathological changes including vacuolation, necrosis, and protein casts were observed in proximal renal tubules on the second day after CP injection in rats [3,5,6,39]. Mukhopadhyay et al. [40] observed that cisplatin-induced mitochondrial ROS generation triggered inflammatory response, cell death, and kidney dysfunction/nephropathy. Cisplatin initially triggers oxidative stress in the mitochondria of kidney proximal tubular and endothelial cells, which is followed by a secondary wave of ROS/RNS (reactive nitrogen species) generation, deterioration of mitochondrial structure and function, an intense inflammatory response, histopathological injury and diminished renal function. Inflammation may further amplify oxidative/nitrative stress, and these interrelated processes eventually culminate in more concerted renal tubular and endothelial cell demise (both apoptotic and necrotic), secondary hypoxia, kidney dysfunction, and failure [40]. A single systemic dose of mitochondrially targeted antioxidants, MitoQ or Mito-CP, dose-dependently, prevented cisplatininduced renal dysfunction. Mito-CP also prevented mitochondrial injury and dysfunction, renal inflammation, and tubular injury and apoptosis [40]. Recent studies showed protective effects of $\mathrm{CoQ}_{10}$ and Vit $\mathrm{E}$ against Cd-induced oxidative stress [41].

A large number of natural products and dietary components have been evaluated as potential chemoprotective agents. Many experimental studies in animals have demonstrated the ability of Se to prevent carcinogenesis [23]. Supplementation of the antioxidant vitamin C, E, curcumin, Se and other dietary components has been reported to inhibit lipid peroxide in various conditions such as CP-induced nephrotoxicity and hepatotoxicity [12-18,39].

In various studies that investigated the role of oxidant stress in the kidney, lipid peroxides are reported to be increased [13,14,16,18,39]. Enzymatic and non enzymatic antioxidant defense systems are present in the cell to prevent the integrity of biological membranes from oxidative processes caused by free radicals $[42,43]$.

The kidney antioxidant defense system, such as SOD, CAT, GSH-Px, GR, GST activities (Figures 1-5), and reduced GSH concentration (Table 1) significantly decreased in the CP alone treated group of animals compared to the control. CP generates ROS such as superoxide anion $\left(\mathrm{O}_{2}{ }^{-}\right)$ 
and hidroxil radicals $(\mathrm{OH})$, and stimulates kidney lipid peroxidation $[1,8,15,39,40]$. It is accepted that both correlate to oxidative stress and cause the imbalance between the generation of oxygen derived radicals and the organism's antioxidant potential $[42,43]$. CP-induced suppression of kidney antioxidant defense enzyme activity was also supported by the recently published experimental results $[9,13,14]$.

The decrease in SOD activity (Figure 1) after CP administration might be due to the loss of copper and zinc which are essential for the activity of enzyme or to ROS induced inactivation of enzyme proteins $[13,18,39]$. CP has been demonstrated to induce the loss of copper and zinc in the kidneys. The decreased SOD activity is insufficient to scavenge the superoxoide anion, produced during the normal metabolic process $[42,43]$. The activities of CAT and GSH-Px (Figures 2 and 3) were also found to decrease after $\mathrm{CP}$ administration, resulting in the decreased ability of the kidney to scavenge toxic hydrogen peroxide $\left(\mathrm{H}_{2} \mathrm{O}_{2}\right)$ and lipid peroxides. $\mathrm{CP}$ administration resulted in a decline of GSH concentration (Table 1) and a decrease of GR and GST activities (Figures 4 and 5) in the rat kidney. The results from the present study indicate that Se significantly reduces the depletion of GSH concentration and antioxidant defense enzyme activity in the kidney of rat treated with CP. The protective effects of Se seem to be primarily associated with its presence in the GSH-Px, which is known to protect DNA and other cellular components from damage by ROS. Selenoenzymes are also known to play roles in carcinogen metabolism, in the control of cell division, oxygen metabolism, detoxification processes, apoptosis induction, and the functioning of the immune system [19-21,24,25].

GSH is necessary for resistance to oxidative stress through detoxification of ROS. It can also detoxify many endogenous toxins, including CP, through the formation of GSH adducts $[7,17,44,45]$. In addition, the GSH redox cycle, which includes GSH, GSH-Px and GR, plays an important role in the detoxification of ROS that are generated by $\mathrm{CP}$, so as to protect cells from the potential toxicity and carcinogenesis $[17,18,44,46]$. The primary symptoms of cisplatin nephrotoxicity are inhibition of protein synthesis and intracellular GSH and protein-SH depletion, resulting in lipid peroxidation and mitochondrial damage $[2,10,44,45]$. GSH and protein-SH form the major cellular antioxidant defense systems, which control lipid peroxidation. The reduced renal GSH can markedly increase the toxicity of CP. The depletion of GSH also seems to be a prime factor that permits lipid peroxidation in the CP-treated group. The treatment with Se was very effective in the prevention of oxidative damage induced by $\mathrm{CP}$, which resulted in significantly increased GSH concentration [47]. Experimental studies demonstrated that exogenous GSH could offer protection against CP-induced renal injury. Thiols, such as the sulfur of GSH, bind to the platinum molecule, replacing one of the chloride ions, thus preventing binding to other cellular nucleophiles [45]. The increased intracellular GSH concentration correlated with decreased platinum-DNA binding in freshly isolated peripheral blood mononuclear cells [6]. Studies of tumor cell lines have shown a correlation between the increased levels of intracellular GSH and the resistance to CP $[44,45]$.

GSH-Px, in particular, is highly dependent on GSH concentration. GSH-Px metabolizes $\mathrm{H}_{2} \mathrm{O}_{2}$ to water by using GSH as a hydrogen donor, resulting in the formation of GSSG [46,48]. GR subsequently regenerates GSH from GSSG. The decrease in the GSH-Px activity may result in the involvement of deleterious oxidative changes due to the accumulation of toxic products. The Se-containing enzyme GSH-Px protects cells against ROS. This result indicates that the increase in MDA in the kidney of rats treated with CP may be related to the decrease in the activity of GSH-Px. In this study, administration of Se exhibits GSH-Px-like activity, which prevented the decrease of GSH-Px activity in the kidney. 
Yoshida et al. [49] and Naziroğlu et al. [13] showed that the reduction of GSH-Px activity in the kidney tissue of rats treated with $\mathrm{CP}$ alone was prevented by co-treatment with Se.

The GST enzyme has an important role in detoxification of xenobiotics, drugs, and carcinogens, thus protecting the cells against redox cycling and oxidative stress. The decrease in the GST activity or -SH group could explain the induction of free radicals in CP-treated rats [16]. GST is a family of enzymes that catalyzes the conjugation of GSH to a variety of substrates. Several isoforms of GST have been shown to bind $\mathrm{CP}$ in vivo [44,50]. In the studies where increased resistance to $\mathrm{CP}$ was observed, none determined whether the inactivation of CP was due to GST binding to the CP, or catalyzing its conjugation to GSH. The previous studies show that after incubation of blood platelets with CP, the amount of GSH decreased and the complex of cisplatin with GSH (GS-cisPt) was formed (via reaction catalysed by GST) [50,51]. Feinfeld et al. [52] and Badary et al. [16] showed that the rats given a single toxic dose of CP excreted detectable GST activity in their urine, thus suggesting that urinary GST activity was a marker for a CP-induced proximal tubular damage.

The treatment with Se reversed the CP induced alterations of all examined parameters in rat kidney. The results indicate that Se significantly reduced the depletion of GSH concentration and antioxidant defense enzyme activity in the kidney of rats treated with $\mathrm{CP}$, thus providing protection to the kidney. The protective effect of Se against CP-induced oxidative stress in this study could also be either direct, by inhibiting lipid peroxidation and scavenging free radicals [13,47], or indirect, through the enhancement of the activity of antioxidant defense enzymes including SOD, CAT and GSH-Px [9].

Se can reduce the nephrotoxicity and hepatotoxicity of $\mathrm{CP}$ without reducing the antitumor activity of the drug $[13,20]$. The protection correlates with higher levels of Se in the kidney and with higher concentration of GSH in the kidney, both compared to tumors. Se is known to protect GSH by forming the selenodiglutathione complex [24]. It is known that substitution reactions with biologic nucleophiles appear to govern the antitumor and toxic properties of platinum complexes [53]. Selenite is metabolized into selenols, specifically into methylselenol and glutathionylselenol, while bioactivation of selenite into selenols is a GSH-dependent process. HPLC with on line radioactivity detection of ${ }^{195 \mathrm{~m}} \mathrm{Pt}$ showed that methylselenol $\left(\mathrm{HSe}-\mathrm{CH}_{3}\right)$ was capable of forming a complex with $\mathrm{CP}$ in vitro. ${ }^{1} \mathrm{H}-\mathrm{NMR}$ gave evidence that the complex contained one or more $\mathrm{Pt}-\mathrm{Se}-\mathrm{CH}_{3}$ bonds. It is proposed that the formation of a CP-selenol complex also takes place in vivo, especially in the kidney, thereby preventing CP to exert its nephrotoxic activity [23,47]. The biological roles ascribed to Se include the prevention of cancer [19,54,55], cardiovascular disease and viral mutation [20-26,56].

\section{Conclusions}

In conclusion, we have shown that CP-induced nephrotoxicity is closely associated with the increase of lipid peroxidation in the kidney tissues. Treatment with CP causes significant changes in the activity of antioxidant defense enzymes (SOD, CAT, GSH-Px, GR and GST) and GSH concentration. The results of our study suggested that the treatment with Se reversed CP-induced lipid peroxidation and alterations in antioxidant defense system, and significantly prevented CP-induced kidneys damage. Our results showed that the nutritional antioxidant Se ameliorated oxidative stress and loss of cellular antioxidants and suggested that Se efficiently protected kidneys from CP-induced oxidative damage. 


\section{Acknowledgements}

This study was supported by the Ministry of Science of Republic of Serbia, grant no. 173041. The authors are thankful to MSc Radmila Paunović Štajn for proofreading this article.

\section{Conflict of Interest}

The authors declare that there are no conflicts of interest.

\section{References}

1. Baek, S.M.; Kwon, C.H.; Kim, J.H.; Woo, J.S.; Jung, J.S.; Kim, Y.K. Differential roles of hydrogen peroxide and hydroxyl radical in cisplatin-induced cell death in renal proximal tubular epithelial cells. J. Lab. Clin. Med. 2003, 142, 178-186.

2. Hanigan, M.H.; Devarajan, P. Cisplatin nephrotoxicity: Molecular mechanisms. Cancer Ther. 2003, 1, 47-61.

3. Jordan, P.; Carmo-Fonseca, M. Molecular mechanisms involved in cisplatin cytotoxicity. Cell Mol. Life Sci. 2000, 57, 1229-1235.

4. Kroning, R.; Lichestenstein, A.K.; Nagami, G.T. Sulfur-containing amino acids decrease cisplatin cytotoxicity and uptake in renal tubular epithelial cell lines. Cancer Chemother. Pharmacol. 2000, 45, 43-49.

5. Cohen, S.M.; Lippard, S.J. Cisplatin: From DNA damage to cancer chemotherapy. Prog. Nucleic Acis. Res. Mol. Biol. 2001, 67, 93-130.

6. Sadowitz, P.D.; Hubbard, B.A.; Dabrowiak, J.C.; Goodisman, J.; Tacka, K.A.; Aktas, M.K.; Cunningham, M.J.; Dubowy, R.L.; Souid, A.K. Kinetics of cisplatin binding to cellular DNA and modulations by thiolblocking agents and thiol drugs. Drug Metab. Dispos. 2002, 30, 183-190.

7. Mora, L.O.; Antunes, L.M.G.; Francescato, H.D.C.; Bianchi, M.L.P. The effects of oral glutamine on cisplatin-induced nephrotoxicity in rats. Pharmacol. Res. 2003, 47, 517-522.

8. Matsushima, H.; Yonemura, K.; Ohishi, K.; Hishida, A. The role of oxygen free radicals in cisplatin-induced acute renal failure in rats. J. Lab. Clin. Med. 1998, 131, 518-526.

9. Cetin, R.; Devrim, E.; Kilicoglu, B.; Avei, A.; Candir, O.; Durak, I. Cisplatin impairs antioxidant system and causes oxidation in rat kidney tissues: Possible protective roles of natural antioxidant foods. J. Appl. Toxicol. 2006, 26, 42-46.

10. Zhang, J.G.; Lindup, W.E. Role of mitochondria in cisplatin-induced oxidative damage exhibited by rat renal cortical slides. Biochem. Pharmacol. 1993, 45, 2215-2222.

11. El-Daly, E.S. Protective effect of cysteine and vitamin E, Crocus sativus and Nigella sativa extracts on cisplatin-induced toxicity in rats. J. Pharm. Belg. 1998, 53, 87-95.

12. Kim, Y.K.; Jung, J.S.; Lee, S.H.; Kim, Y.W. Effects of antioxidants and $\mathrm{Ca}^{2+}$ in cisplatin-induced cell injury in rabbit renal cortical slices. Toxicol. Appl. Pharmacol. 1997, 146, 261-269.

13. Naziroğlu, M.; Karaoglu, A.; Askoy, A.O. Selenium and high dose vitamin E administration protects cisplatin-induced oxidative damage to renal, liver and lens tissues in rats. Toxicology 2004, 195, 221-230. 
14. Atessahin, A.; Yilmaz, S.; Karahan, I.; Ceribasi, A.O.; Karaoglu, A. Effects of lycopene against cisplatin-induced nephrotoxicity and oxidative stress in rats. Toxicology 2005, 212, 116-123.

15. Atessahin, A.; Sahna, E.; Türk, G.; Ceribasi, A.O.; Yilmaz, S.; Yüce, A.; Bulmus, O. Chemoprotective effect of melatonin against cisplatin-induced testicular toxicity in rats. J. Pineal. Res. 2006, 41, 21-27.

16. Badary, O.A.; Abdel-Maksoud, S.; Ahmed, W.A.; Owieda, G.H. Naringenin attenuates cisplatin nephrotoxicity in rats. Life Sci. 2005, 76, 2125-2135.

17. Yüce, A.; Atessahin, A.; Ceribasi, A.O.; Aksakal, M. Ellagic acid prevents cisplatin-induced oxidative stress in liver and heart tissue of rats. Basic Clin. Pharmacol. Toxicol. 2007, 101, 345-349.

18. Atasayar, S.; Gürer-Orhan, H.; Orhan, H.; Gürel, B.; Girgin, G.; Özgüneş, H. Preventive effect of aminoguanidine compared to vitamin $\mathrm{E}$ and $\mathrm{C}$ on cisplatin-induced nephrotoxicity in rats. Exp. Toxicol. Pathol. 2009, 61, 23-32.

19. Combs, G.; Gray, W.P. Chemopreventive agents: Selenium. Pharmacol. Ther. 1998, 79, 179-192.

20. Caffrey, P.B.; Frenkel, G.D. Selenium compounds prevent the induction of drug resistance by cisplatin in human ovarian tumor xenografts in vivo. Cancer Chemother. Pharmacol. 2000, 46, 74-78.

21. Chen, J.; Berry, M.J. Selenium and selenoproteins in the brain and brain diseases. J. Neurochem. 2003, 86, 1-12.

22. Saito, Y.; Yoshida Y.; Akazawa, T.; Takahashi, K.; Niki, E. Cell death caused by selenium deficiency and protective effect of antioxidants. J. Biol. Chem. 2003, 278, 39428-39434.

23. Agay, D.; Sandre, C.; Ducros, V.; Faure, H.; Cruz, C.; Alonso, A.; Roussel, A.M.; Chancerelle, Y. Optimization of selenium status by a single intraperitoneal injection of $\mathrm{Se}$ in Se-deficient rat: Possible application to burned patient treatment. Free Radic. Biol. Med. 2005, 39, 762-768.

24. Kim, Y.S.; Combs, J.G.F. Effects of dietary selenium and vitamin E on glutathione concentrations and glutathione S-transferase activities in chick liver and plasma. Nutr. Res. 1993, 13, 455-463.

25. Dilsiz, N.; Ölçücü, A.; Çay, M.; Nazıroğlu, M.; Çobanoglu, D. Protective effects of selenium, vitamin $\mathrm{C}$ and vitamin $\mathrm{E}$ against oxidation stress of cigarette smoke in rats. Cell Biochem. Funct. 1999, 17, 1-7.

26. Ognjanović, B.I.; Marković, S.D.; Pavlović, S.Z.; Žikić, R.V.; Štajn, A.Š.; Saičić, Z.S. Effect of chronic cadmium exposure on antioxidant defense system in some tissues of rats: Protective effect of selenium. Physiol. Res. 2008, 57, 403-411.

27. Jihen, E.H.; Imed, M.; Fatima, H.; Abdelhamid, K. Protective effects of selenium (Se) and zinc $(\mathrm{Zn})$ on cadmium $(\mathrm{Cd})$ toxicity in the liver of the rat: Effects on the oxidative stress. Ecotoxicol. Environ. Saf. 2009, 72, 1559-1564.

28. Su, L.; Wang, M.; Yin, S.T.; Wang, H.L.; Chen, L.; Sun, L.G.; Ruan, D.Y. The interaction of selenium and mercury in the accumulations and oxidative stress of rat tissues. Ecotoxicol. Environ. Saf. 2008, 70, 483-489.

29. Schrauzer, G.N. Selenium and selenium-antagonistic elements in nutritional cancer prevention. Crit. Rev. Biotechnol. 2009, 29, 10-17.

30. Gregus, Z.; Gyurasics, A.; Csanaky, I. Effects of arsenic-, platinum- and gold-containing drugs on the disposition of exogenous selenium in rats. Toxicol. Sci. 2000, 57, 22-31. 
31. Ohkawa, H.; Okishi, N.; Yagi, K. Assay for lipid peroxides in animal tissues by thiobarbituric acid reaction. Anal. Biochem. 1979, 95, 351-358.

32. Misra, H.P.; Fridovich, I. The role of superoxide anion in the autoxidation of epinephrine and simple assay for superoxide dismutase. J. Biol. Chem. 1972, 247, 3170-3175.

33. Beutler, E. Catalase. In Red cell Metabolism, a Manual of Biochemical Methods; Beutler, E., Ed.; Grune and Stratton: New York, NY, USA, 1982; pp. 105-116.

34. Tamura, M.; Oschino, N.; Chance, B. Some characteristics of hydrogen and alkylhydroperoxides metabolizing systems in cardiac tissue. J. Biochem. 1982, 92, 1019-1031.

35. Glatzle, D.; Vulliemuier, J.P.; Weber, F.; Decker, K. Glutathione reductase test with whole blood, a convenient procedure for the assesment of the riboflavin status in humans. Experientia 1974, 30, 665-667.

36. Habig, W.H.; Pabst, M.J.; Jakoby, W.B. Glutathione-S-transferase. J. Biol. Chem. 1974, 249, 7130-7139.

37. Beutler, E. Reduced Glutathione (GSH). In Red Cell Metabolism, a Manual of Biochemical Methods; Beutler, E., Ed.; Grune and Straton: New York, NY, USA, 1975; pp. 112-114.

38. Lowry, O.H.; Rosebrough, N.J.; Farr, A.L.; Randall, R.J. Protein measurement with the Folin phenol reagent. J. Biol. Chem. 1951, 193, 265-267.

39. Antunes, L.M.G.; Darin, J.D.C.; Bianchi, M.L.P. Protective effects of vitamin C against cisplatin-induced nephrotoxicity and lipid peroxidation in adult rats: A dose-dependant study. Pharmacol. Res. 2000, 41, 405-411.

40. Mukhopadhyay, P.; Horváth, B.; Zsengellér, Z.; Zielonka, J.; Tanchian, G.; Holovac, E.; Kechrid, M.; Patel, V.; Stillman, I.E.; Parikh, S.M.; et al. Mitochondrial-targeted antioxidants represent a promising approach for prevention of cisplatin-induced nephropathy. Free Radic. Biol. Med. 2011, doi:10.1016/j.freeradbiomed.2011.11.001.

41. Ognjanović, B.I.; Marković, S.D.; Djordjević, N.Z.; Trbojević, I.S.; Štajn, A.Š.; Saičić, Z.S. Cadmium-induced lipid peroxidation and changes in antioxidant defense system in the rat testes: Protective role of coenzyme $\mathrm{Q}_{10}$ and Vitamin E. Reprod. Toxicol. 2010, 29, 191-197.

42. Matés, M. Effects of antioxidant enzymes in the molecular control of reactive oxygen species toxicology. Toxicology 2000, 153, 83-104.

43. Halliwell, B.; Gutteridge, J.M.C. Free Radicals in Biology and Medicine, 4th ed.; Oxford University Press: New York, NY, USA, 2007.

44. Hrubisko, M.; Mc Gown, A.T.; Fox, B.W. The role of metallothionein, glutathione, glutathione S-transferases and DNA repair in resistance to platinum drugs in a series of L1210 cell lines made resistant to anticancer platinum agents. Biochem. Pharmacol. 1993, 45, 253-256.

45. Chen, G.; Hutter, K.J.; Zeller, W.J. Positive correlation between cellular glutathione and acquired cisplatin resistance in human ovarian cancer cells. Cell Biol. Toxicol. 1995, 11, 273-281.

46. Griffith, O.W. Biologic and pharmacologic regulation of mammalian glutathione synthesis. Free Radic. Biol. Med. 1999, 27, 922-935.

47. Baldew, G.S.; Mol, J.G.J.; de Kanter, F.J.J.; Baar, B.V.; de Goeij, J.J.M.; Vermeulen, N.P.E. The mechanism of interaction between cisplatin and selenite. Biochem. Pharmacol. 1991, 41, 1429-1437.

48. Sies, H. Glutathione and its cellular functions. Free Radic. Biol. Med. 1993, 27, 916-921. 
49. Yoshida, M.; Itzuka, K.; Hara, M.; Nishijima, H.; Shimada, A.; Nakada, K.; Satoh, Y.; Akama, Y.; Terada, A. Prevention of nephrotoxicity of cisplatin by repeated oral administration of ebselen in rats. Tohoku J. Exp. Med. 2000, 191, 209-220.

50. Sadzuka, Y.; Shimizu, Y.; Takino, Y. Role of glutathione S-transferase isoenzymes in cisplatin-induced nephrotoxicity in the rat. Toxicol. Lett. 1994, 70, 211-222.

51. Olas, B.; Washowicz, B.; Bald, E.; Glowacki, R. The protective effects of resveratrol against changes in blood platelet thiols induced by platinum compounds. J. Physiol. Pharmacol. 2004, 55, 467-476.

52. Feinfeld, D.A.; Fuh, V.L.; Safirstein, R. Urinary glutathione-S-transferase in cisplatin nephrotoxicity in the rat. J. Clin. Chem. Clin. Biochem. 1986, 24, 529-532.

53. Dedon, P.C.; Borch, R.F. Characterization of the reactions of platinum antitumor agents with biologic and nonbiologic sulfur-containing nucleophiles. Biochem. Pharmacol. 1987, 36, 1955-1964.

54. Conklin, K.A. Dietary antioxidans during cancer chemotherapy: Impact on chemotherapeutic effectiveness and development of side effects. Nutr. Cancer 2000, 37, 1-18.

55. Schweizer, U.; Bräuer, A.U.; Köhrle, J.; Nitsch, R.; Savaskan, N.E. Selenium and brain function: A poorly recognized liaison. Brain Res. Rev. 2004, 45, 164-178.

56. Wu, Q.; Huang, K. Effect of long-term Se deficiency on the antioxidant capacities of rat vascular tissue. Biol. Trace Elem. Res. 2004, 98, 73-84.

(C) 2012 by the authors; licensee MDPI, Basel, Switzerland. This article is an open access article distributed under the terms and conditions of the Creative Commons Attribution license (http://creativecommons.org/licenses/by/3.0/). 